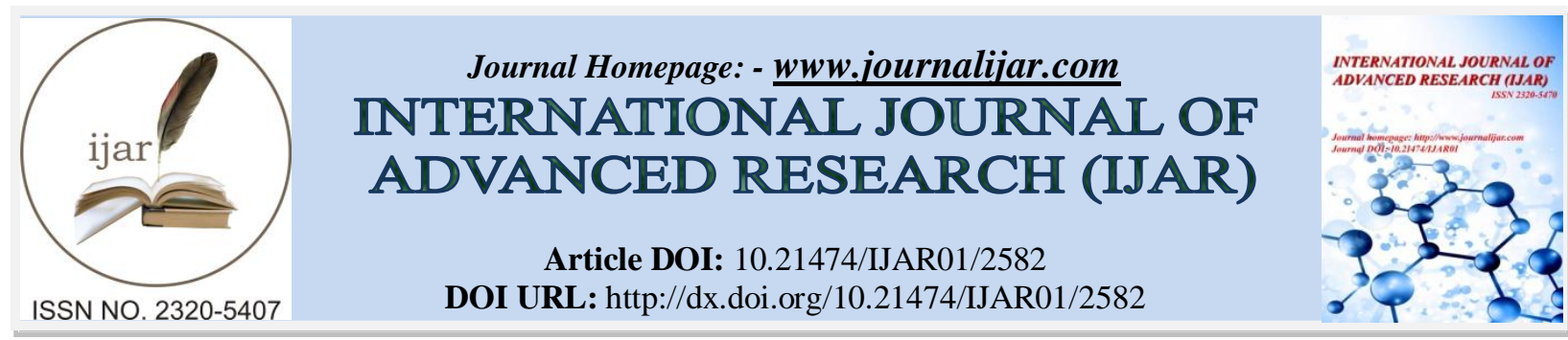

RESEARCH ARTICLE

\title{
A STUDY ON AWARENESS AND PREVENTIVE PRACTICES OF COBBLESTONE WORKERS ON OCCUPATIONAL HAZARDS IN ADDIS ABABA, ETHIOPIA.
}

\section{Hailemariam Mamo (MSc) $)^{1}$ and Yoseph A. Mengesha (MD, PhD) ${ }^{2}$.}

1. Department of Biological Sciences, Dire Dawa University, Dire Dawa, Ethiopia

2. Department of Physiology, School of Medicine, College of Health Sciences, Addis Ababa University Addis Ababa, Ethiopia

\section{Manuscript Info}

\section{Manuscript History}

Received: 27 October 2016

Final Accepted: 25 November 2016

Published: December 2016

Key words:-

Cobblestone work, Awareness,

Occupational Hazards, Preventive

Practice, Personal Protective Devices

\section{Abstract}

Cobblestone work has been becoming a good job opportunity in Ethiopia.Workers have involved in cutting, drilling, handling, loading, transporting, chiseling and paving activities that expose them to various occupational hazards. This study was designed to assess awareness and preventive practices of cobblestone workers towards occupational hazards in Addis Ababa, Ethiopia. Cross sectional study and random sampling was used. Totally,155 (82 chiseling and 73 quarry) workers were participated. Questionnaire, structured interview and observational checklist were used for data collection. Workers awareness and preventive practices were found to be very low. Their habit to utilize personal protective devices and availability were too limited. Workers should be trained and appropriate personal protective devices should be accessible to them. Policy and guidelines should be developed for regular inspection and for co-operation between workers and competent authorities.

Copy Right, IJAR, 2016,. All rights reserved.

\section{Introduction:-}

Ethiopia is rapidly growing, mainly the construction sector is booming. Cobble stone projects are one of the major constructions upgrading minor roads, side roads, and walk ways within towns and cities. Cobblestone is small rounded stone used for paving. The project includes the quarry excavation, chiseling and paving activities. It has been becoming a good job opportunity for a good number of citizens because of its comparative advantages. It does not require sophisticated skill, knowledge and machineries. It is also labour-intensive involving huge number of working forces utilizing local resources. However, during activities of cobblestone work, workers have been injured and exposed to hazards during excavating, cutting, drilling, handling loading, transporting, chiseling and paving activities [1-3].

Occupational hazards during occupational activities cause occupational diseases and injuries [1,2]. Various cancer types, cardio respiratory diseases, diseases of the nervous system, noise-induced hearing loss, vibration disorders and various causes of fatal and non-fatal injuries are known [3]. Additionally, new occupational diseases, such as mental and musculoskeletal disorders are on the rise [1].

Many studies depict that occupations involving stone materials have adverse effects on health [4,5]. Fine dust in the underground and from stone could have metals and other substances that are risky for human health. The effects of 
stone dust exposure on the cardio-respiratory function, liver and kidney has been reported [4]. Most rocks and soil contains silica in quartz and crystalline form associated with human diseases including silicosis, lung cancer, chronic obstructive pulmonary disease, emphysema and pulmonary tuberculosis [6-9]. Millions of workers continue to be at risk of pneumoconiosis (silicosis and asbestos related diseases) due to widespread exposures to silica, coal, asbestos and various mineral dusts in mining, quarrying, construction and other manufacturing processes [3,10-11].

Occupational safety and health is entrusted with essentially preventive functions and advising the employer, workers and their representatives [12]. It is a key element in achieving sustained decent working conditions and strong preventive safety cultures [13]. Surveillance of workers health, working environment, provision of information, personal protective devices and training to workers shall be implemented [14, 15]. Every worker has moral and legal responsibility to care for his/her safety and other co-workers [16]. This study assessed the awareness and preventive practices of cobblestone workers about hazards from working activities.

\section{Materials and Methods:-}

The present study was conducted on cobblestone (chiseling and quarry) workers in Addis Ababa from eight sites. Cross sectional study and random sampling was used. About, 155 (82 chiseling and 73 quarry) workers were participated. Questionnaire, interview and observation were used for data collection. Descriptive statistics was used for data analysis. The sampling population was the chiseling and quarry workers. The participants $(\mathrm{N}=155)$ were quarry $(n=73(47.1 \%)$ and chiseling $(n=82(52.9 \%)$ workers. The quarry workers were all males while the chiseling workers involved both male $(\mathrm{M}=59)$ and female $(\mathrm{F}=21)$ workers. Among nine working sites the Hana Mariam, Chefe $a$ and Hidase sites were selected randomly and systematically considering the number of workers and duration of site establishment. Statistical product and Service Solution (SPSS) for windows version 20.0 was used to analyze data while Microsoft Excel 2010 was used to arrange and organize the data.

\section{Results:-}

Some demographic characteristics such as educational and marital status of study participants were analyzed for some implications in addition to variables that indicate workers level of awareness and preventive practices towards occupational hazards. Most of participants were illiterate and elementary level. More than half of them were single.

Table 1:- Educational and marital status of study participants.

\begin{tabular}{|l|l|}
\hline Educational and marital status & Number $(\%)$ \\
\hline \multicolumn{1}{|l|}{ Educational status } & \\
\hline Illiterate & $23(15.9)$ \\
\cline { 2 - 2 } $\begin{array}{l}\text { Elementary } \\
\text { Secondary }\end{array}$ & $76(52.4)$ \\
\cline { 2 - 2 } Tertiary & $40(27.6)$ \\
\cline { 2 - 2 } 2. Marital status & $6(4.1)$ \\
\hline Single & \\
\hline Married & $79(54.5)$ \\
\hline Divorced & $59(40.7)$ \\
\hline Widowed & $6(4.1)$ \\
\hline
\end{tabular}

Cobblestone workers had limited awareness on occupational hazards that can arise from work related activities. The habit to utilize personal protective devices was very low. None of them utilized eye goggles, glove, respirator and apron. Some participants responded that they sometimes utilize helmet, face mask, coverall, safety shoes and other means. 


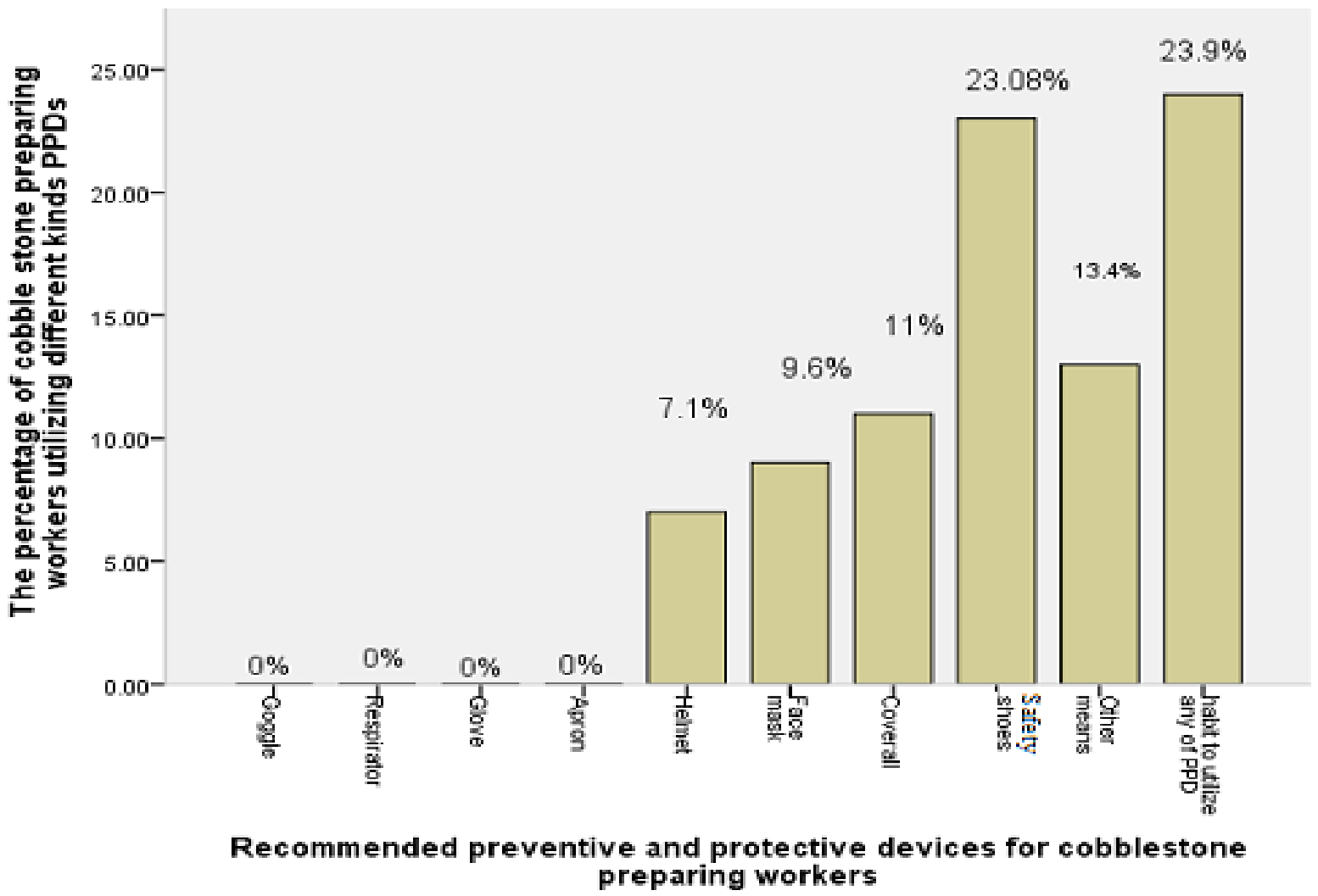

Figure 1:- Workers habit in personal protective devices utilization.

About 58.7\% workers were aware of the impact of dust on their health. About 56.8\% workers believed that exposure to dust have effect on lung and respiratory tract while $44.5 \%$ had thought that it could cause heart problems.

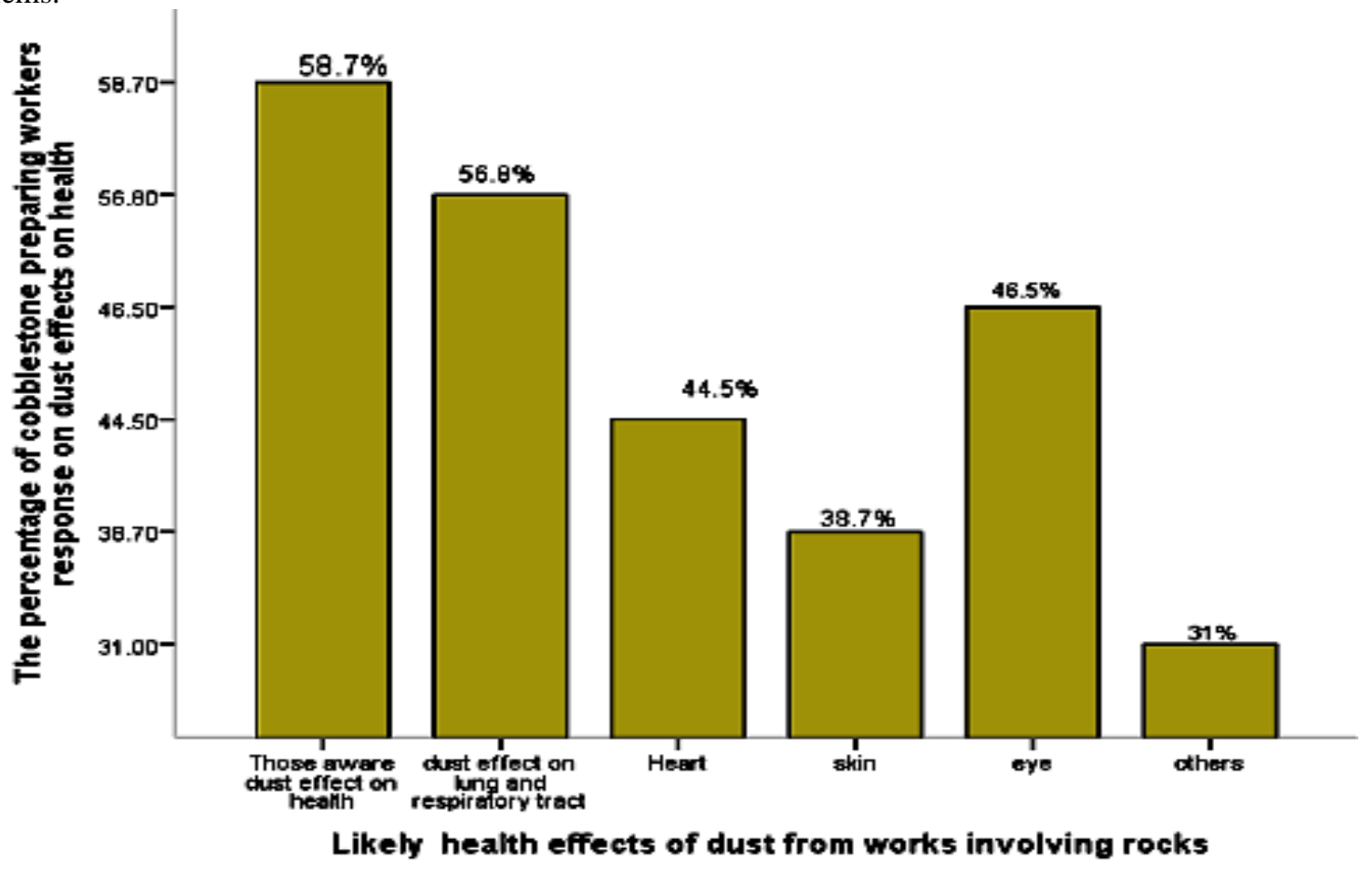

Figure 2:- The awareness of workers on the dust effect on health conditions. 
Cobblestone workers require access to facilities that minimize dust hazards. The study participants were requested to respond about the access of facilities in working sites or nearer. About $12.3 \%$ of participants said they had access of personal protective devices. As far as access to training about occupational safety and hazards is concerned, $13.5 \%$ workers agreed that there were access. About $2.6 \%$ of the cobblestone workers reported that they had access to medical treatment whenever diseases or injuries occurred.

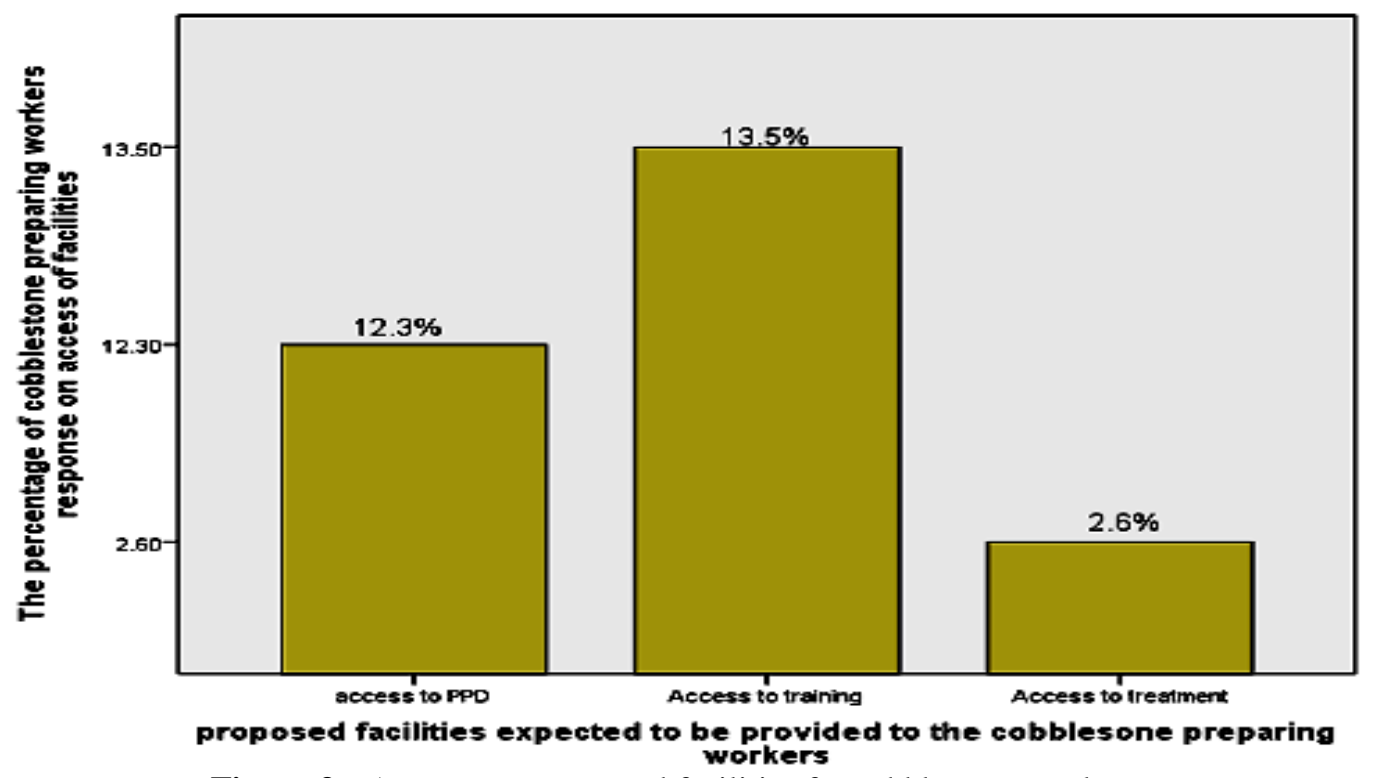

Figure 3:- Accesses to supposed facilities for cobblestone workers

\section{Discussion:-}

In Ethiopia, studies on knowledge, awareness and practices of workers to occupational hazardous are inadequate. Some studies indicated that workers had lower awareness and preventive practices. A study on farm workers in Ethiopia depicted that workers habit on personal protective equipment utilization was very low. Although personal protective devices were provided to handle hazardous pesticides and insecticides; workers were reluctant to use it regularly [17].

Similarly, the present study showed lack of awareness and poor practice to use personal protective devices among the cobblestone workers. None of the respondents utilize goggle, glove, respirator and apron. Among the study participants, $7.1 \%, 9.6 \%, 11 \%$, and $23.08 \%$ had utilized helmet, face mask, coverall and safety shoes, respectively. About only $23.0 \%$ participants had habit to use any of personal protective devices and equipment.

From study participants, about $58.7 \%$ had awareness about the impact of dust on their health. About $56.8 \%$ workers believed that exposure to dust has effect on lung and respiratory tract while $44.5 \%$ of them thought it could cause heart problems. About $38.7 \%, 46.5 \%$ and $31 \%$ of workers claimed that stone dust could have effect on skin, eye and other health problems, respectively. A study conducted in some selected factory workers showed very limited knowledge, awareness and preventive practices towards occupational hazards and injuries [18].

Occupational safety and health requires safe working conditions and strong preventive safety practices [12, 13]. Workers should have access to information, personal protective devices and trainings $[14,15]$. About $12.3 \%$ of study participants had used personal protective devices. Only $13.5 \%$ participants had obtained training on occupational safety and hazards. About $2.6 \%$ of the workers agreed that they had access to medical treatment. Cobblestone workers in study areas had inadequate health facilities, PPDs and training access. Health care providers were recruited in each cobblestone work sites but, most workers claimed that there were no access to medicines, necessary medical equipments and better first aid implements. They added that the only heath services that were provided included wound wash, bandage and pain killers.

Ethiopia shows its commitment on occupational hazards reduction preparing legislations and confirms to abide the international labor organization. But, workers are facing problems that affect their working environments and health status. Construction and factory workers have had complain about unsafe working environment, inadequate or lack 
of personal protective devices and proper insurance when injured. There were neither regular medical check-up nor proper protection of workers against adverse occupational hazards. [18].

\section{Conclusion:-}

The study showed that access and habit to utilize personal protective device and awareness of cobblestone workers were very low. Most of the workers never use PPDs for various reasons. Lack of awareness, inadequate supply and access of facilities were some reasons. Significant number of workers did not know the likely health trouble of occupational hazards related to cobble stone work activities. Although health professionals were assigned, workers were not satisfied because of very limited medical treatment, scarce supply of medical equipment and drugs in the first aid centers. The working environment was also unsafe.

\section{Recommendation:-}

The protection of workers' health against the occupational hazards at the workplace should be the concern of all of those involved in the design, organization and performance of the work and health professionals. From this study it is recommended that workers should be trained. Modern technologies and machineries should be introduced to reduce various risky exposures. Workers need to get access to appropriate personal protective devices, protective clothing and safety shoes. Wetting of working surface reduces dust. Occupational health professionals should be recruited and effective legal and administrative frameworks for the prevention and reduction of hazards and risks should be developed. Workers should abide by instructions given to them about hazards and injuries to protect their own health as well as that of their colleagues.

\section{References:-}

1. International Labour Organization; the Prevention of Occupational Diseases. World Day for Safety and Health at Work. 28 April, 2013.

2. Mariammal T., Amutha Jaisheeba A. and Sornaraj R. Work Related Respiratory Symptoms and Pulmonary Function Tests Observed Among Construction and Sanitary Workers of Thoothukudi. International Journal of Pharm Tech Research CODEN (USA): 2012;Vol. 4: No.3: 1266-1273.

3. Driscoll T. The burden of occupational disease and injury in New Zealand: Technical Report. NOHSAC: Wellington, 2004.

4. Matt Loxham. Microscopic dust particles found in underground railways may pose health risk. Phys.org. University of Southampton. 2013.

5. Nwibo A; Pulmonary Problems among Quarry Workers of Stone Crushing Industrial Site at Umuoghara, Ebonyi State, Nigeria. The International Journal of Occupational and Environmental Medicine.2012; 3:178-185.

6. Government of Alberta, Human Services. Occupational Health and Safety Bulletin. Crystalline Silica at the Work Site, Chemical Hazards Revised November: 2009

7. Occupational Knowledge International (OKI). Silica Geary Boulevard, San Francisco, 2013

8. Ugbogu O.C., Ohakwe J. and Foltescu V. Occurrence of respiratory and skin problems among manual stonequarrying workers. African Journal of Respiratory Medicine,2009, 23-26

9. Dirk Demol; Assessment of exposure in epidemiological studies: the example of silica dust. Journal of Exposure Science and Environmental Epidemiology. 2008; 18: 452-461

10. Safe Workplace Promotion Services (SWPS). Silica in the Workplace. 2011

11. Crystalline Silica exposure health hazard information. Informational fact sheets High lighting Occupational safety and health administrative OSHA U.S.A department of labor, 2002.

12. Federal Democratic Republic of Ethiopia Ministry of Labour and Social Affairs. Occupational Safety and Health Directive. Addis Ababa, May, 2008.

13. Occupational exposure to airborne substances harmful to health. International Labour Office Geneva, 1980.

14. Meeting of experts on ambient factors in the workplace: An ILO code of practice Geneva: International Labour Organization. In: UNESCO-UNEVOC International Centre Publications. 2000.

15. Occupational Health and Safety. An Annotated Bibliography of Research and Related Literature (1998-2003), UNESCO. Website: http//www.unevoc.unesco.org/publication. Published on July, 2004. Accessed on June, 2013.

16. Safety, health and welfare on construction sites; A training manual International Labour Organization Geneva, 1999.

17. Yalemtsehay Mekonnen and Tadesse Agonafir. Personal Protective Equipment use by farm workers in Ethiopia Pesticides News No. 55, March 2002, page 15

18. Mengesha Y.A. and Bekele A. Effect of acute exposure to different occupational dusts on pulmonary function indices of factory workers in Ethiopia. Afr newslett on occup health and safety 1997; 714-16 